Journal of Social Sciences (COES\&RJ-JSS)

ISSN (E): 2305-9249 ISSN (P): 2305-9494

Publisher: Centre of Excellence for Scientific \& Research Journalism, COES\&RJ LLC

Online Publication Date: $1^{\text {st }}$ October 2017

Online Issue: Volume 6, Number 4, October 2017

https://doi.org/10.25255/jss.2017.6.4.734.743

\title{
The Effect of Music Therapy on Sleep Quality of Cancer Patients Undergoing Chemotherapy or Radiotherapy: A Randomized control trial
}

\author{
SeemaVinayak*, Farnaz Dehkhoda**, RohinVinayak*** \\ *Department of Psychology, PanjabUniversity, Chandigarh, India \\ ** Ph.D Scholar, Psychology Department, Panjab University, Chandigarh, India \\ ** MBBS Student, Dayanand Medical College and Hospital, Ludhiana, India
}

\begin{abstract}
:
Poor sleep quality is frequent in patients undergoing cancer treatment such as chemotherapy and radiotherapy. In the present study, an effectiveness of music therapy on the quality of sleep in cancer patients was evaluated. 184 adult cancer patients undergoing chemotherapy or radiotherapy were selected from the population who met the inclusion criteria based on convenience sampling. They were randomly assigned to three groups: two intervention groups of active or receptive music therapy and a control group. Participants completed Pittsburgh Sleep Quality Index at pre-intervention and postintervention stages. Ten sessions of active or receptive music therapy were applied to the intervention groups, while the control group received only routine medical care. Every session was of 20-30 minutes. Receptive music therapy involved patient's preferred Persian pop music, and active music therapy involved playing guitar and singing under training and supervision of a music-therapist. Two-way Analysis of Covariance indicated significant differences between results of pre-test and post-test on sleep quality in both intervention groups. It showed the effectiveness of music therapy in experimental groups, as compared to the control group, and revealed active music therapy to be more effective to improve sleep quality. No gender difference was found on the results. The study has great implications for sleep quality improvement in the cancer patients undergoing chemotherapy and radiotherapy.
\end{abstract}

Keywords:

Cancer, Chemotherapy, Music therapy, Radiotherapy, Sleep quality

\section{Citation:}

Vinayak, Seema; Dehkhoda, Farnaz; Vinayak, Rohin (2017); The Effect of Music Therapy on Sleep Quality of Cancer Patients Undergoing Chemotherapy or Radiotherapy: A Randomized control trial; Journal of Social Sciences (COES\&RJ-JSS), Vol.6, No.4, pp:734-743; https://doi.org/10.25255/jss.2017.6.4.734.743. 


\section{Introduction}

Cancer diagnosis is a stressful event and can cause psychological collapse in patients. Subsequently, cancer treatments such as chemotherapy and radiotherapy can cause many psychological and physical symptoms; for example depression, anxiety, pain and sleep disorders (Theobald, 2004; Mercadante, Gireli \& Casuccio, 2004; Aynur, Declan \& Rybicki, 2010). Evidently, sleep is one of the important vital daily needs of human beings. Sleep disturbance in cancer patients is reported more than the general population (Parker et al. 2008). After cancer treatments such as chemotherapy or radiotherapy, patients reported that their sleep quality was significantly reduced without any change in their sleep style (Zarogoulidis et al. 2013). In heterogeneous advanced oncology patients, 72\% who reported sleep disturbance had common complaints about trouble in sleep onset and upkeep; not feeling rested in the morning, and feeling fatigue throughout the day (Sela, Watanabe \& Nekolaichuk, 2005). Sleep disturbance accrues in cancer patients who are under treatment, and is characterized by falling asleep with effort, staying asleep, deprived sleep efficacy and extreme day tiredness (Zarogoulidis et al. 2013). Troubled sleep can cause poor healing and increase chances of cancer recurrence (Ancoli-Israel, Moor \& Jones, 2001; Anderson, Getto, Mendoza et al. 2003). Chemotherapy and radiotherapy in cancer patients cause poorer sleep quality significantly (Owen, Parker \& McGuire, 1999) and sleepiness in daytime (KuoChiu, Liao \& Hwang, 2009).

Sleep disturbance includes the adverse effect that is reported by cancer patients under chemotherapy and radiotherapy very repeatedly (Davidson et al. 2002; O'Donnell, 2004; Berger et al. 2005; Kvale \& Shuster, 2006; Whitmer et al. 2006). Due to the high percentage of poor sleep in quality and quantity in oncology patients, sleep-related studies and symptom management have been included in several psychological interventions to improve sleep problems and increase the quality of life in cancer patients. Several pharmacological and psychological therapies were widely prescribed to treat sleep disorders and daytime fatigue that is a result of low sleep quality at night in cancer patients, but these treatments did not achieve certain results (Mustian et al., 2007). If people comprehend that sleep is influenced by both physiological and psychological factors, then different kinds of spiritual-physical interventions such as music therapy, can be considered to be used from the first days (Cervellin \& Lippi, 2011).

In recent years, the tendency to use non-medicine methods in improving sleep quality has been increased (Tang et al. 2015). Music therapy as an intervention is a useful, reasonable and an accessible therapy (McCaffrey, 2008). American Music Therapy Association (2014) has defined the music therapy as a part of psychological services: "clinical and evidence-based use of music interventions to accomplish individualized goals within a therapeutic relationship by a credentialed professional who has completed an approved music therapy program". Music can influence the limbic system of the brain, the modulation of endogenous opioids and oxytocin, thus improving sleep (Bernatzky, Presch, Anderson \& Panksepp, 2011). According to a psychological theory, music makes a relaxation response that can decrease neuro endocrine and sympathetic nervous system activities, which may cause reduction of stress, anxiety and increaseof sleep quality (Chan, Chan \& Mok, 2010).

While sleep problem has so many physical and psychological side effects, quality of sleep can affect quality of life too, yet as an important item in cancer patient's life, sleep quality has not been considered and researched extensively. Sleep deprivation can cause many 
physical and psychological problems such as fatigue, restless legs, insomnia, daytime sleepiness, anxiety and depression (Onen, Alloui, Gross, Eschallier \& Dubray, 2001). Cancer patients, undergoing chemical and radiological treatment as particular cases of sleep problems, need more care.

\section{Review of Literature}

In oncology patients, interrupted sleep is appraised as the second most annoying symptom on the basis of cancer and treatment status (Otte et al. 2015). In many studies it has been concluded that music improves the sleep quality among different types of population (Jespersen \& Vuust, 2012; Ryu, Park \& Park, 2012; Bloch et al. 2010; Deshmukh, Sarvaiya, Seethalakshmi \& Nayak, 2009; Harmat et al. 2008; Lai \& Good, 2005; Hernandez-Ruiz, 2005; Johnson, 2003; Kullich et al. 2003; Renzi, Peticca \& Pescatori, 2000; Richards, 1998; and Zimmerman, Nieveen, Barnason, \& Schmaderer, 1996). All these studies have shown that music has a statistically significant sleep-promoting effect, thus a sedative music intervention was expected to improve sleep quality. These results indicated that music is a potential non-pharmacological intervention for the treatment of sleep disturbances such as insomnia.

Previous studies have investigated the positive effect of music therapy on sleep quality by relaxing, controlling the mind and positive thought and expectations (de Niet, Tiemens, Lendemeijer \& Hutschemaekers, 2009; Harmat, Takács \& Bódizs, 2008).

There is a lack of research in the area of positive effect of music therapy on cancer patients undergoing treatment. The only investigation found in this area was Lafçi and Öztunç's (2015) research on effect of music therapy on sleep quality of breast cancer patients, that just applied receptive classical music therapy and the result showed that it was an effective intervention in reducing sleeping problems.

The objective of the present study was to examine the efficacy of active and receptive music therapy sessions in improving sleep quality in cancer in patients undergoing chemotherapy or radiotherapy and comparing the measure of effectiveness in males and females. It was hypothesized that active music therapy is more effective than receptive music therapy in improving sleep quality of cancer patients. In contrast to receptive music therapy techniques such as listening to music, active music therapy techniques include engaging the client in singing and playing the musical instrument. The majority of the techniques that constitute clinical music therapy are active music therapy techniques. Based on fMRI and PET scan studies, active music participation in comparing to receptive music therapy engages more parts of the brain (AMTA, 2014).

\section{Materials and Methods}

The study was performed for determining the ability of music therapy to improve sleep quality among cancer patients undergoing oncology treatments.

\section{Sample}

Participants were cancer inpatients, both males and females, undergoing chemotherapy or radiotherapy in adult cancer unit of three government hospitals in Golestan Province, Iran. 184 patients were studied to detect the difference between the three groups viz. control group, receptive music therapy group and active music therapy group. The initial sample size in pre-test was of 240 patients (127 males and 113 females). After pre-test the 
participants were randomly assigned to either the experimental groups or control group. Fifty-six patients were dropped-out for the following reasons: leaving the chemotherapy sessions, not being interested to participate anymore, physical inability, death, and incomplete questionnaires.

Inclusion criteria were: age range of 20 to 40 years old, with at least one month of cancer diagnosis, undergoing chemotherapy or radiotherapy, not diagnosed with any psychological disorder and interested in playing the guitar. Some patients were excluded from the study: those who had voice sensitive epilepsy, the ones were not interested in music, and those who had inability to see sufficiently to mark the Visual Analog Scale.

\section{Procedures and Measurements}

Participants received ten sessions of active or receptive music therapy in two intervention groups. Each session was twenty to thirty minutes spread over ten days. The reason that we decided to do the research on hospitalized patients was patients were more available for the scheduled therapeutic sessions. In receptive music therapy, pop music was played for each individual by using MP3 player (depending on their choice of songs). In one presession, they were asked about their top 10 favorite songs of pop music and in the first session the music therapist instructed them how to use MP3 players. Active music therapy was conducted based on group therapy (each group comprised 10-12 individuals). In a pre-session one Persian pop song was chosen by the patients of the groups and during all ten sessions a guitar player specialist trained the patient show to play their selected song by guitar,and the patients sang the song during the sessions. The scores based on the scale were given once before and after therapy. This study is an experimental research and every patient received individual sessions of receptive music therapy. Active music therapy has been done in groups of 10-12, either males or females separately.In control group, participants received routine nursing cares. Pre-test and post-test design was applied in the present investigation. For estimating sleep quality and sleep disturbances over the last month, the self-rated questionnaire, Pittsburgh Sleep Quality Index (PSQI), was administered. Farrahi Moghaddam et al. (2012) assessed the reliability and the validity of Persian version of the Pittsburgh Sleep Quality Index.

The trial was conducted in the oncology department of the governmental hospitals in Golestan state, where they are affiliated to the medical science universities of Iran.

\section{Statistical Analysis}

Descriptive statistics, viz mean and standard deviation were calculated. The analysis of covariance (ANCOVA) was conducted to compare the effectiveness of three different interventions on the sleep quality among cancer patients.

\section{Ethics}

In this study, all cancer patients were aware about the nature of the music therapy method and gave their consent to participatein the study.

\section{Results}

In ANCOVA, post-intervention scores were considered as dependent variable, the independent variable was the type of intervention (control group, receptive music therapy and active music therapy). The participant's scores of the sleep quality on the preintervention were considered as covariate. 
The Effect of Music Therapy on Sleep Quality of Cancer Patients ......

Table 1. Descriptive Statistics, Means, Standard Deviations for Group Differences on sleep-quality

\begin{tabular}{|c|c|c|c|c|}
\hline \multicolumn{2}{|c|}{ Group } & Mean & Std. Deviation & $\mathrm{N}$ \\
\hline \multirow{3}{*}{$\begin{array}{c}\text { Receptive } \\
\text { music therapy }\end{array}$} & Male & 9.5667 & 2.20788 & 32 \\
\hline & Female & 9.7667 & 1.97717 & 30 \\
\hline & Total & 9.6667 & 2.08031 & 62 \\
\hline \multirow{3}{*}{$\begin{array}{c}\text { Active music } \\
\text { therapy }\end{array}$} & Male & 8.0333 & 2.12511 & 30 \\
\hline & Female & 8.9333 & 2.54522 & 28 \\
\hline & Total & 8.4833 & 2.36852 & 58 \\
\hline \multirow{3}{*}{ Control group } & Male & 12.2000 & 2.12376 & 35 \\
\hline & Female & 11.9667 & 2.37056 & 29 \\
\hline & Total & 12.0833 & 2.23449 & 64 \\
\hline \multirow{3}{*}{ Total } & Male & 9.9333 & 2.74292 & 97 \\
\hline & Female & 10.2222 & 2.62134 & 87 \\
\hline & Total & 10.0778 & 2.67923 & 184 \\
\hline
\end{tabular}

Table 2. Tests of Between-Subjects Effects

\begin{tabular}{|c|c|c|c|c|c|}
\hline Source & $\begin{array}{c}\text { Type III Sum of } \\
\text { Squares }\end{array}$ & Df & $\begin{array}{c}\text { Mean } \\
\text { Square }\end{array}$ & F-value & $\begin{array}{c}\mathrm{p}- \\
\text { value }\end{array}$ \\
\hline Group & 437.675 & 2 & 218.838 & $121.611^{* *}$ & .000 \\
Gender & .304 & 1 & .304 & .169 & .682 \\
Group * & 3.029 & 2 & 1.515 & .842 & .433 \\
Gender & 556.021 & 1 & 556.021 & $308.987 * *$ & .000 \\
$\begin{array}{c}\text { Sleep Quality } \\
\text { Based } \\
\text { Error }\end{array}$ & 311.312 & 176 & 1.799 & & 1 \\
Total & 1284.911 & 183 & & & \\
\hline
\end{tabular}

$* *$ p-value $<0.01=$ highly significant

Table 3. Pairwise Comparisons, Post-Hoc Multiple Comparisons

\begin{tabular}{|c|c|c|c|c|c|c|}
\hline \multirow{2}{*}{\multicolumn{2}{|c|}{ Group }} & \multirow{2}{*}{$\begin{array}{c}\text { Mean } \\
\text { Differenc } \\
\text { e }\end{array}$} & \multirow{2}{*}{$\begin{array}{l}\text { Std. } \\
\text { Erro } \\
\quad \text { r }\end{array}$} & \multirow[b]{2}{*}{$\mathrm{p}$-value } & \multicolumn{2}{|c|}{$\begin{array}{l}\text { 95\% Confidence Interval } \\
\text { for Difference }\end{array}$} \\
\hline & & & & & $\begin{array}{c}\text { Lower } \\
\text { Boun } \\
\text { d }\end{array}$ & Upper Bound \\
\hline \multirow{6}{*}{$\begin{array}{c}\text { Receptiv } \\
\text { e music } \\
\text { therapy } \\
\text { Active } \\
\text { music } \\
\text { therapy } \\
\text { Control } \\
\text { group }\end{array}$} & Active & $.874 * *$ & .246 & .001 & .280 & 1.467 \\
\hline & Control & $-2.786^{* *}$ & .246 & .0001 & -3.380 & -2.192 \\
\hline & $\begin{array}{c}\text { Receptiv } \\
\text { e }\end{array}$ & $-.874 * *$ & .246 & .001 & -1.467 & -.280 \\
\hline & Control & $-3.660 * *$ & .245 & .0001 & -4.252 & -3.067 \\
\hline & $\begin{array}{l}\text { Receptiv } \\
\mathrm{e}\end{array}$ & $2.786 * *$ & .246 & .0001 & 2.192 & 3.380 \\
\hline & Active & $3.660 * *$ & .245 & .0001 & 3.067 & 4.252 \\
\hline
\end{tabular}


**p-value $<0.01=$ highly significant

Figure 1- Graph showing Sleep quality post-test scores among male and female cancer patients on three different groups

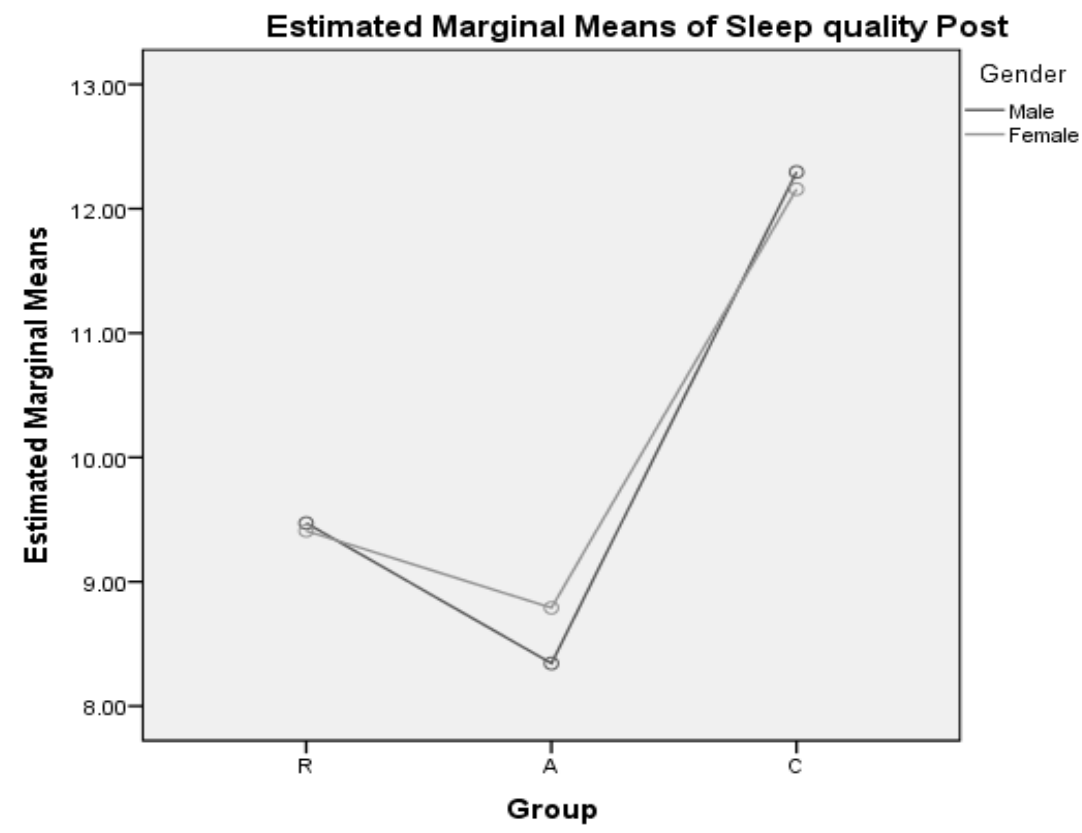

Covariates appearing in the model are evaluated at the following values: Sleep quality Pre $=12.0667$

In preliminary analysis, there was no significant difference between three groups based on sleep quality scores in pre-condition $(\mathrm{F}=0.061)$. Preliminary checks were conducted to ensure that there was no violation of the assumptions of normality, linearity, homogeneity of variances, homogeneity of regression slopes, and reliable measurement of the covariate. Table 2 showed that the main effect of the groups (active music therapy, receptive music therapy, and control group) was statistically significant $(\mathrm{F}=121.61, \mathrm{p} \leq 0.01)$. The main effect of gender and interaction between groups and gender was non-significant. Results revealed highly significant difference in scores on sleep quality of cancer patients $(\mathrm{F}=308.98, \mathrm{p} \leq 0.01)$, which means that the different types of music therapy had a significant impact on sleep quality among cancer patients and this was different in the three groups. Post hoc analysis was done by using multiple comparisons Bonferroni test revealed a significant differencebetween the three groups (Table 3), also represented graphically (Figure1). However, the active music therapy was more effective as compared to the receptive music therapy in improving sleep quality in cancer patients (Table 3, Figure1).

\section{Discussion}

Lack of sleep and inefficient sleep are common problems in cancer patients along the treatment stage from the point of diagnosis to end of life in all stages (Berger et al., 2005; Vena et al., 2004). The purpose of this investigation was to study the effectiveness of two types of music therapy on sleep quality in cancer patients under treatment. The results of the present investigation revealed that both the techniques viz. Receptive music therapy 
and active music therapy improve patients' sleep quality. According to review of literature, there is lack of studies, which compare the effects of active and receptive music therapy as a psychological intervention in cancer patients. Based on the results, a significantly higher mean in the active music therapy group showed that this technique is more beneficial to improve sleep quality of individuals. Thus, the hypothesis was proved.

Previous studies also have shown similar results and have found that active music therapy showed more psychological and physiologically effectiveness on mind and body, thus causing improved sleep quality (Burns, Sledge, Fuller, Daggy, \& Monahan, 2005; Rickson $\&$ Watkins, 2003). According to the neuroscience perspective, receptive and active music therapy can activate different parts of the brain. Receptive music therapy is a type of passive listening to music that involves subcortical and cortical areas of the brain. FMRI and PET scan have shown that active music therapy involves more parts of the brain than receptive music therapy (Yinger \& Gooding, 2014). By participating in music therapy and playing an instrument, such as guitar in active music therapy, clients feel purposeful and confident. The involvement of individuals in playing musical instruments and singing can make their mind busy, therefore, they feel calm at the same moment. Listening and playing music causes the feeling of "here and now" (Gaston, 1968). Music can lead to the relaxation that can reduce stress and arousal, and cause a higher level of well being and sleep quality (Pelletier, 2004).

The researchers have found that both types of music therapy are effective in increasing sleep quality (Johnson, 2003; Abhijeet et al., 2009; Chan et al., 2010). Regarding the duration of music therapy intervention, Chan et al. (2010) suggested that at least four weeks of observation is required to see the effectiveness of intervention on sleep quality, but Zimmerman et al. (1996) have got the results of music therapy in just one session. The present study results are in line with the earlier studies. In this research, music was used as parallel-therapy along with chemotherapy and radiotherapy and applied for ten sessions in ten days and the results showed significant improvement in sleep quality after ten sessions.

Lafçi and Öztunç (2015) found that music therapy positively affects the sleep quality in breast cancer patients, however, the quality of sleep in control group, which did not get music therapy decreased during the period of chemotherapy and radiotherapy treatment. According to Lai and $\mathrm{Li}$ (2011), the improvement of sleep quality in patients after the music therapy might be related to the power of music to decrease stress. However, these studies have only carried out on receptive music therapy and they have not compared the two types of music therapy. This means that their results are limited by single therapy, but in the present study both techniques have been investigated. It came to the conclusion that active music therapy is more effective than receptive music therapy.

The results of the present investigation were in contradiction with research conducted by Lazic and Ogilvie (2007) as they found that music therapy did not cause any improvement in the sleep quality of individuals with or without the sleep disorder. However, no similar comparable and contrastable research with this present study is available.

Considering that no prior research compared gender difference in the study of music therapy effectiveness, present study focused on comparison between male and female oncology patients. However, results revealed no significant difference based on gender 
regarding effectiveness of music therapy on sleep quality.

While the above-mentioned studies have shown that music as a therapy can improve sleep quality, however it has not suggested any specific strategy or method for applying music intervention. Hence, a protocol is needed to show the strategy for applying music therapy with particular consideration on various elements such as music-playing duration in each session, type of music and musical instrument. Furthermore, it is essential to understand which kind of ambience is required to make the suitable environment for patients. It could be added that the efficiency of these interventions depends on patients' satisfaction (Nilsson, 2011) and the patient-preferred music is a useful method to increase the level of enjoyment and effectiveness of music therapy (Lai, 2004).

\section{Research Limitations and Suggestions}

When the limitations of the study are considered, the type of music seems to be the first limitation of our study. As it was Persian pop music, different results may be obtained with different types of music. However, it should be taken into consideration that the efficiency of English pop music was found in other studies and that, the music tracks were selected by the participants. The lack of sufficient scientific evidence caused limitation in the approval of effectiveness of music in young adult cancer patients. It has risks of bias. As a first bias, since the therapist was present at the therapeutic sessions, both therapist and patient are not in the blinded situation, it can increase the risk of bias in the group assignment. When the patients are not blinded in the intervention for reporting subjects such as sleep quality, overestimation or underestimation may occur as the second risk of bias. (Bradt, Dileo, Grocke\& Magill, 2011). Another limitation is the therapy duration that was less than one month, and was ten sessions in ten days. There is a need to check whether the effect of music therapy is sustainable or will give better results after the follow-up or not.

The strength points of the present study arelarge sample size and using two types of music therapy intervention. Music therapy is an easy, affordable and accessible intervention. Through this study it has been proved that it can improve sleep quality in young adult patients with chronic disease such as cancer. Though the type of music used in this study was pop Persian music, and the instrument was guitar, for the future investigations, this paper suggests two ideas. Firstly, a comparison between the two types of music therapy on sleep quality is required. Secondly, in order to increase the sleep quality in patients who suffer from chronic disease, the effectiveness of the other styles and types of music and musical instruments should be considered. For the future studies, it is also recommended to expand the effectiveness of musical instrument playing and singing while the patient undergoes chemotherapy or radiotherapy.

\section{Acknowledgment}

The authors wish to thank all the patients, who have participated in the investigation project and also are grateful to the officials and the oncologists at the Sayad Shirazi Hospital, $5^{\text {th }}$ Aazar Hospital and Falsafi Hospital in Golestan state, Iran, for their sincere cooperation. 


\section{References}

- $\quad$ American Music Therapy Association. (2014). http://www.musictherapy.org.

- $\quad$ Ancoli-Israel, S., Moore, P. J. \& Jones, V. (2001). The relationship between fatigue and sleep in cancer patients: a review. European journal of Cancer Care, 10(4): 245-55.

- $\quad$ Anderson, K.O., Getto, C.J., Mendoza, T.R., et al. (2003). Fatigue and sleep disturbance in patients with cancer, patients with clinical depression, and communitydwelling adults. Journal of Pain Symptom Management, 25: 307-318.

- $\quad$ Aynur, A., Declan, W. \&Rybicki, L. (2010). Review: symptom clusters: myth or reality. Palliative Medical journal, 24, 373-85.

- $\quad$ Berger, A. M., Parker, K. P., Young-McCaughan, S., Mallory, G. A., Barsevick, A. M., Beck, S. L., et al. (2005). Sleep wake disturbances in people with cancer and their caregivers: state of the science. Oncology Nursing Forum, 32: 98-126.

- $\quad$ Bernatzky G, Presch M, Anderson M, Panksepp J (2011) Emotional foundations of music as a non-pharmacological pain management tool in modern medicine. Neuroscience Bio-behavior Review Journal, 35: 1989-1999.

- $\quad$ Bloch, B., Reshef, A., Vadas, L., Haliba, Y., Ziv, N. et al. (2010). The effects of music relaxation on sleep quality and emotional measures in people living with schizophrenia. Journal of Music Therapy, 47: 27-52.

- $\quad$ Bradt J., Dileo C., Grocke D. \& Magill L. (2011). Music interventions for improving psychological and physical outcomes in cancer patients. Cochrane Database System Review, 8:CD006911

- $\quad$ Burns, D. S., Sledge, R. B., Fuller, L. A., Daggy, J. K., \& Monahan, P. O. (2005). Cancer patients' interest and preferences for music therapy. Journal of Music Therapy, 42(3), 185-199.

- $\quad$ Cervellin, G. \& Lippi, G. (2011). From music-beat to heartbeat: a journey in the complex interactions between music, brain and heart. European Journal of Internal Medicine, 22 (4), 371-374.

- $\quad$ Chan M.F., Chan, E.A. \&Mok, E. (2010). Effects of music on depression and sleep quality in elderly people: a randomized controlled trial. Complementary Therapies in Medicine, 18 (3-4), 150-159.

- $\quad$ Davidson, JR., Maclean, AW., Brundage, MD. \& Schulze, K. (2002). Sleep Disturbance In Cancer Patients. Social Science and Medical Journal, 54, 1309-21.

- deNiet, G., Tiemens, B., Lendemeijer, B. \&Hutschemaekers, G. (2009). Musicassisted relaxation to improve sleep quality: meta-analysis. Journal of Advanced Nursing, 65 (7), 1356-1364.

- $\quad$ Deshmukh, AD., Sarvaiya, A.A., Seethalakshmi, R. \&Nayak, AS. (2009). Effect of Indian classical music on quality of sleep in depressed patients: A randomized controlled trial. Nordic Journal of Music Therapy, 18: 70-78.

- FarrahiMoghaddam J, Nakhaee N, Sheibani V, et al. (2012). Reliability and validity of the Persian version of the Pittsburgh Sleep Quality Index (PSQI-P. Journal of Sleep Breath. 79-82. doi: 10.1007/s11325-010-0478-5.

- $\quad$ Gaston, E. T. (1968). Music in therapy. New York, NY: Macmillan.

- Harmat, L., Takacs, J., \&Bodizs, R. (2008). Music improves sleep quality in students. Journal of Advanced Nursing, 62(3), 327-335. doi:10.1111/j.13652648.2008.04602.x

- Hernandez-Ruiz, E. (2005). Effect of music therapy on the anxiety level and sleep patterns of abused women in shelters. Journal of Music Therapy, 42 (2), 140-158.

- Jespersen, KV. \&Vuust, P. (2012). The Effect of Relaxation Music Listening on 
Sleep Quality in Traumatized Refugees: A Pilot Study. Journal of MusicTherapy, 49: 205229.

- Johnson, JE. (2003). The use of music to promote sleep in older women. Journal of Community Health Nursing, 20: 27-35.

- $\quad$ Kullich, W., Bernatzky, G., Hesse, H.P., Wendtner, F., Likar, R. \& Klein, G. (2003). Music therapy effect on pain, sleep and quality of life in low back pain. Wiener MedizinischeWochenschrift, 153 (9-10), 217-221.

- $\quad$ Kuo, H., Chiu, M., Liao, W. \& Hwang, SL. (2009). Quality of sleep and related factors during chemotherapy in patients with stage I/II breast cancer. Journal of Formosan Medical Association, 105:64-69.

- $\quad$ Kvale, EA. \& Shuster, JL. (2006). Sleep disturbance in supportive care of cancer: a review. Palliative Medicine Journal, 9, 437-51.

- $\quad$ Lafçi, D. \&Öztunç, G. (2015). The Effect of Music on The Sleep Quality of Breast Cancer Patients. International Journal of Caring Sciences, 21(3)164-171. doi: 10.5455/GMJ-30-175101.

- $\quad$ Lai, H.L. \& Good, M. (2005). Music improves sleep quality in older adults. Journal of Advanced Nursing, 49 (3), 234-244.

- Lai, HL. (2004). Music preference and relaxation in Taiwanese elderly people. Geriatric Nursing Journal, 25: 286-291.

- $\quad$ Lazic, S., \& Ogilvie, R. (2007). Lack of efficacy of music to improve sleep: A polysomnographic and quantitative EEG analysis. International Journal of Psychophysiology, 63, 232-239. doi: 10.1016/j.ijpsycho.2006.10.004.

- $\quad$ Lutz, S., Norrell, R., Bertucio, C., et al. (2001). Symptom frequency and severity in patients with metastatic or locally recurrent lung cancer: a prospective study using the lung cancer symptom scale in a community hospital. Palliative Medicine Journal, 4, 15765 .

- McCaffrey, R. (2008). Music listening: its effects in creating a healing environment. Journal of Psychosocial Nursing and Mental Health Service, 46: 39-44.

- Mercadante, S., Gireli, D., Casuccio, A. (2004). Sleep Disorders In Advanced Cancer Patients:Prevalence And Factors Associated”. Support Care Cancer Journal, 12, 355-9.

- $\quad$ Mustian, KM., Morrow, GR., Carroll, JK., Figueroa-Moseley, CD., Jean-Pierre, P., Williams, GC. (2007). Integrative non-pharmacologic behavioral interventions for the management of cancer-related fatigue. The Oncologist Journal, 1:52-67.

- Nilsson, U. (2011) Music: a nursing intervention. European Journal of Cardiovascular Nursing, 10: 73-74.

- O’Donnell, JF. (2004). Insomnia in cancer patients. Journal of Clinical cornerstoner, 6, 6-14.

- $\quad$ Onen SH, Alloui A, Gross A, Eschallier A, Dubray C. (2001). The effects of total sleep deprivation, selective sleep interruption and sleep recovery on pain tolerance thresholds in healthy subjects. Journal of Sleep Researches. 10:35-42.

- Otte JL., Carpenter JS., Manchanda S., Rand KL., Skaar TC., Weaver M., Chernyak Y., Zhong X., Igega C., Landis C. (2015). Systematic review of sleep disorders in cancer patients: can the prevalence of sleep disorders be ascertained?CancerMed; 4(2):183-200. doi: 10.1002/cam4.356.

- $\quad$ Owen, D.C., Parker, K.P. \& McGuire, D.B. (1999). Comparison of subjective sleep quality in patients with cancer and healthy subjects. Oncology Nursing Forum, 26:16491651 . 
- $\quad$ Parker, K.P., Bliwise, D.L., Ribeiro, M., et al. (2008). Sleep/wake patterns of individuals with advanced cancer measured by ambulatory polysomnography. Journal of Clinical Oncology, 26:2464-2472.

- $\quad$ Pelletier, C. L. (2004). The effect of music on decreasing arousal due to stress: A meta-analysis. Journal of Music Therapy, 41(3), 192-214.

- $\quad$ Renzi, C., Peticca, L. \&Pescatori, M. (2000). The use of relaxation techniques in the perioperative management of proctological patients: preliminary results. International Journal of Colorectal Disease, 15 (5-6), 313-316.

- $\quad$ Richards, KC. (1998). Effect of a back massage and relaxation intervention on sleep in critically ill patients. American Journal of Critical Care, 7: 288-299.

- Rickson, D., \& Watkins, W. G. (2003). Music therapy to promote prosocialbehaviours in aggressive adolescent boys: A pilot study. Journal of Music Therapy, 40(4), 283-301.

- $\quad$ Ryu, MJ., Park, JS., Park, H. (2012). Effect of sleep-inducing music on sleep in persons with percutaneous transluminal coronary angiography in the cardiac care unit. Journal of Clinical Nursing, 21: 728-735.

- $\quad$ Sela, R.A., Watanabe, S. \&Nekolaichuk, C.L. (2005). Sleep disturbances in palliative cancer patients attending a pain and symptom control clinic. Palliative Support Care, 3:23-31.

- $\quad$ Tang NK, Lereya ST, Boulton H, Miller MA, Wolke D, Cappuccio FP. (2015). Nonpharmacological Treatments of Insomnia for Long-Term Painful Conditions: A Systematic Review and Meta-analysis of Patient-Reported Outcomes in Randomized Controlled Trials. Journal of Sleep, 1751-64. doi: 10.5665/sleep.5158.

- $\quad$ Theobald, ED. (2004). Cancer pain, fatigue, distress, and insomnia in cancer patients. Clinical Cornerstone Journal, 6, 15-21.

- $\quad$ Vena, C., Parker, K., Cunningham, M., Clark J. \& McMillan, S. (2004). Continuing education: sleep-wake disturbances in people with cancer part I: an overview of sleep, sleep regulation, and effects of disease and treatment. Oncology Nursing Journal Forum, 31:735-746.

- $\quad$ Whitmer, MK., Pruemer, JM., Nahleh, ZA. \&Jazieh, AR. (2006). Symptom management needs of oncology outpatients. Palliat Med, 9, 628-30.

- $\quad$ Yinger, O. S., and Gooding, L. (2014). Music therapy and music medicine for children and adolescents. Child Adolescents Psychiatry Clinics of North America, 23, 535-553. doi: 10.1016/j.chc.2013.03.003.

- $\quad$ Zarogoulidis, P., Steiropoulos, P., Perantoni, E. et al. (2013). Subjective sleep quality in lung cancer patients before and after chemotherapy. Thoracic Cancer journal, 4 , $138-42$.

- $\quad$ Zimmerman L., Nieveen, J., Barnason, S. \&Schmaderer, M. (1996). The effects of music interventions on postoperative pain and sleep in coronary artery bypass graft (CABG) patients. Scholarly Inquiry for Nursing Practice. 10 (2), 153-170. 